\title{
The Validity of Carotid Doppler Peak Velocity and Inferior Vena Cava Collapsibility Index in Identifying the Fluid Responders in Mechanically Ventilated Septic Shock Patients
}

\author{
Mohamed Soliman (D), Ahmed Magdi(D), Moataz Fatthy (D), Rania El-Sherif(D) \\ Department of Critical Care Medicine, Cairo University, Giza, Egypt
}

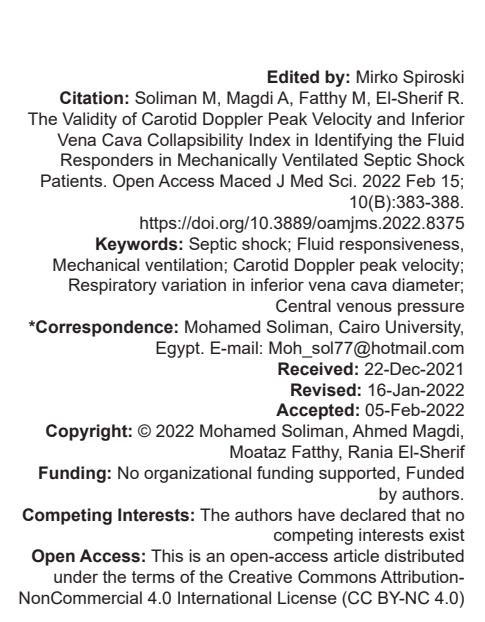

Introduction

Sepsis is defined as life-threatening organ dysfunction due to a deregulated host response to infection which can result in grave complications such as septic shock which is a subset of infection with circularity and cellular/metabolic dysfunction associated with a higher risk of mortality [1]. One of the lines for the treatment is to administer intravenous fluids as the first step to improve blood pressure [2]. A fluid challenge will cause an increase in stroke volume only when patients' cardiac preload is in the low volume status [3], [4]. Determining the optimal amount of fluid to be administered remains a critical issue through continued inquiry. Analysis of large databases suggests that there may be a U-shaped response curve, where limited amounts as well as large amounts of fluid administration are associated with worse outcomes. The best response was observed when fluid resuscitation was administered in volumes between 15 and $45 \mathrm{~mL} / \mathrm{kg}$ [5]. However, studies have shown that not every patient advantages from aggressive intravenous hydration [6]. Only $40 \%$ of hypotensive patients with sepsis respond to it with improvement in blood pressure [2], [7]. Those who do not respond are liable to develop high intravascular pressure, pulmonary edema, or acute heart failure with high associated mortality [8], [9], [10].

Therefore, precise fluid resuscitation and careful assessment of fluid responsiveness should be fastidiously evaluated and always weigh between the benefits and the risks of intravenous fluids [11]. Static indicators of fluid responsiveness such as central venous pressure (CVP) and pulmonary capillary wedge pressure are poor predictors of fluid responsiveness [12], [13]. In contrast, indices relying on the cardiopulmonary interactions in mechanically ventilated patients have been shown to be good predictors of fluid responsiveness [13]. Respiratory variation in aortic blood peak velocity had high sensitivity and specificity to predict fluid responsiveness [14], [15], However, measurements of aortic blood flow velocity need a transesophageal ultrasound which is an invasive procedure. Several studies had been done to evaluate the noninvasively respiratory variation of brachial artery peak velocity flow to predict fluid responsiveness in mechanically ventilated patients and concluded that it is a feasible tool for predicting fluid responsiveness, with 
efficiency similar to other well-known dynamic parameters of preload [16], [17]. Measures of carotid artery flow or inferior vena cava (IVC) diameter (IVC-d) were recently shown to predict fluid responsiveness [16], [17], [18].

\section{Aim of the study}

Our aim is to assess the fluid responsiveness by measuring carotid Doppler peak velocity and respiratory variation in IVC-d against the increase in the cardiac index by echocardiographic calculations as a reference in mechanically ventilated patients in septic shock.

\section{Methods}

This is a multicenter, prospective, and cohort study on 30 critically ill mechanically ventilated patients in septic shock. We included in our study only patients who were mechanically ventilated and in septic shock for which the treating intensivist was considering fluid challenge and titration of vasopressor doses based on patients' response to therapy. The study was performed in Cairo University Intensive Care Unit, Assalam International Hospital, and Al Safa Hospital for 1 year. We excluded patients <18 years, shock other than septic shocks, known cardiac disease, end-stage renal disease who required hemodialysis, intra-abdominal hypertension, and carotid artery stenosis $>55 \%$. All the patients were subjected to IV fluid bolus by $7 \mathrm{ml} / \mathrm{kg}$ crystalloid solution over $30 \mathrm{~min}$. Static and dynamic indices were obtained before fluid bolus (TO) and after fluid bolus (T1) by a well-trained echocardiography operator. Patients who achieved an increase of $15 \%$ or more in the cardiac output - calculated by echocardiography - after the fluid challenge were classified as "responders" (R), and those with an increase of $<15 \%$ in CO or those with no increase were classified as "non-responders" (NR). CVP, mean arterial pressure, pulse pressure, difference between diameters of IVC during inspiration and expiration $(\Delta \mathrm{IVC}-\mathrm{d})$ in single respiratory cycle, and difference between velocities of carotid Doppler peak velocity in single respiratory cycle ( $\triangle \mathrm{CDPV})$ were all measured by the same well-trained echocardiography operator then data were calculated and followed (Figure 1).

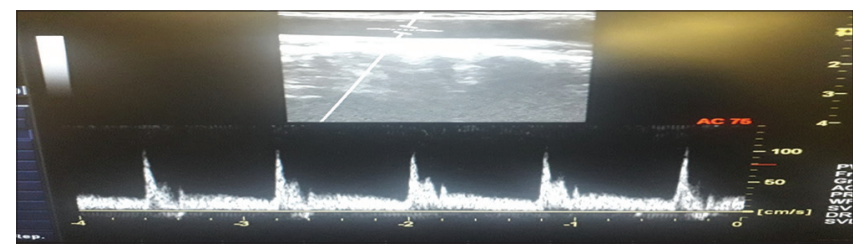

Figure 1: Measurement of variation in carotid peak systolic velocity. At $50 \%$ in this patient
Carotid peak systolic velocity was measured using a $5-10-\mathrm{mHz}$ linear array transducer. Devices used were: GE LOGIQ ${ }^{\mathrm{TM}}$ P9- South Korea, FUJIFILM SonoSite M-Turbo®- Malaysia.

At $50 \%$ in this patient and Toshiba Xario ${ }^{\mathrm{TM}}$ 200- Japan: Maximum and minimum peak systolic velocitieswere measured inasingle respiratory cycle, and the respiratory variation in carotid Doppler peak velocity " $\triangle \mathrm{CDPV}$ " was calculated with the following formula: $\frac{(\text { MaxCDPV }- \text { MinCDPV }) /(\text { MaxCDPV }+ \text { MinCDPV })}{2} \times 100$,

expressed as a percentage [18]. IVC-d measurement was performed with a two views IVC using 2-6 $\mathrm{MHz}$ curved transducer with longitudinal two views at a subxyphoidal long axis just caudal to the hepatic vein inlet. Devices used were: GE LOGIQ $^{\text {TM }}$ P9- South Korea, FUJIFILM SonoSite M-Turbo®- Malaysia, and Toshiba Xario ${ }^{\mathrm{TM}}$ 200- Japan. Maximum and minimum diameters over a single respiratory cycle were recorded and respiratory variation in IVC-d was calculated with the formula: $\frac{(\text { Max IVC }-d-\text { Min IVC }-d) /(\text { Max IVC }-d+\text { Min IVC }-d)}{2} \times 100$ expressed as a percentage [19].

Cardiac output was measured using a 1.5-7-mHz phased array transducer. Devices used were: GELOGIQ ${ }^{\mathrm{TM}}$ P9- South Korea, FUJIFILM SonoSite M-Turbo®- Malaysia, and Toshiba Xario ${ }^{\mathrm{TM}}$ 200- Japan. Two views were obtained: Long parasternal view and apical five chambers view. Measurement of LVOT diameter was obtained in the parasternal long axis view during systole while assess LVOT Velocity Time Integral: Using pulsed wave Doppler in the apical five chamber view. Stroke volume was calculated with the formula: Stroke volume = left ventricle outflow tract "LVOT" area × LVOT velocity time interval "VTI" = Pi"3.14" (LVOT diameter/2) ${ }^{2}$ x LVOT VTI [20]. Then, cardiac output was calculated by formula: Cardiac output $=$ stroke volume $\times$ heart rate. The parameters on the ventilator were kept constant during data recording. Inotropes or vasopressors rate was not changed and stimulation of the patients was avoided.

Data were summarized by descriptive statistics using mean, standard deviation, median, minimum and maximum in quantitative data, and using frequency (count) and relative frequency (percentage) for categorical data. Mean values and standard deviation were compared using simple t-test (for two variables) or ANOVA test (for more than two variables). Comparisons between quantitative variables were done using the non-parametric Mann-Whitney test [21]. For comparing categorical data, Chi-square $\left(\chi^{2}\right)$ test was performed. Exact test was used instead when the expected frequency is $<5$ [22]. Correlations between quantitative variables were done using Spearman correlation coefficient [23]. ROC curve was constructed with area under curve analysis performed to detect best cutoff value of 
significant parameters for detection of responders. Data were coded and entered using the statistical package Statistical Package for the Social Sciences version 25. $\mathrm{P} \leq 0.05$ was considered statistically significant.

\section{Results}

In our study, we included 30 patients in septic shock on controlled mechanical ventilation according to the inclusion criteria, positive culture results, and need of vasoactive drug infusion. Stroke volume, CVP, IVC-d, and CDPV were measured in all patients before and after fluid boluses. Baseline characteristics of the patients are shown in Table 1.

Table 1: Characteristics and baseline parameters before all fluid challenges between responders and non-responders

\begin{tabular}{|c|c|c|c|}
\hline Variable & Responsive (n: 21) & Non-responsive (n: 9) & $p$-value \\
\hline Age & $64.95 \pm 12.59$ & $68.22 \pm 21.18$ & 0.193 \\
\hline \multicolumn{4}{|l|}{ Gender } \\
\hline Male & $10(48 \%)$ & $6(67 \%)$ & 0.440 \\
\hline Female & $11(52 \%)$ & $3(33 \%)$ & \\
\hline APACHE II & $16.05 \pm 3.23$ & $18.44 \pm 3.81$ & 0.164 \\
\hline SOFA score 0 & $11.48 \pm 2.82$ & $12.11 \pm 2.80$ & 0.625 \\
\hline SOFA score 5 & $12.95 \pm 3.68$ & $12.56 \pm 3.97$ & 0.790 \\
\hline TLC $(\times 103 / \mu \mathrm{l})$ & $17.19 \pm 8.38$ & $18.60 \pm 10.18$ & 0.859 \\
\hline Lactate $(\mathrm{mmol} / \mathrm{l})$ & $6.36 \pm 3.64$ & $8.04 \pm 4.67$ & 0.397 \\
\hline Mortality rate & $17(81 \%)$ & $7(77.8 \%)$ & 1 \\
\hline \multicolumn{4}{|l|}{ Comorbidities } \\
\hline Hypertension & $3(62 \%)$ & $5(56 \%)$ & 1 \\
\hline Diabetes mellitus & $8(38 \%)$ & $5(56 \%)$ & 0.443 \\
\hline Ischemic heart disease & $9(43 \%)$ & $5(56 \%)$ & 0.694 \\
\hline Immunocompromised & $8(38 \%)$ & $5(56 \%)$ & 0.443 \\
\hline Malignancy & $6(29 \%)$ & $4(44 \%)$ & 0.431 \\
\hline $\begin{array}{l}\text { Chronic kidney } \\
\text { disease }\end{array}$ & $3(14 \%)$ & $3(33 \%)$ & 0.329 \\
\hline COPD & $4(19 \%)$ & $1(11 \%)$ & 1 \\
\hline
\end{tabular}

Assessment score, range from 0 to 24 , with higher scores indicating a greater risk of mortality.

Pneumonia was the most common cause of sepsis in our study (42.4\%) followed by soft-tissue infection and urosepsis in six patients each $(18.2 \%$ for each). Acute Physiology and Chronic Health Evaluation II score was calculated for all patients within $24 \mathrm{~h}$ of diagnosis of septic shock (16.8 \pm 3.5$)$. Sequential Organ Failure Assessment (SOFA) score was calculated for all patients within $24 \mathrm{~h}$ of diagnosis of septic shock (SOFA day [1]) and on day 5 (SOFA day [5]); SOFA (1) calculation was $(11.7 \pm 2.8)$, and SOFA (5) calculation was $(12.8 \pm 3.7)$. There was no a single comorbidity that has a significant impact on fluid responding or even can predict how will be the patients react to the fluid boluses. Out of 30 patients who were enrolled in the study, 24 patients (80\%) died and only 6 patients $(20 \%)$ survived. Patients included in the study were segregated according to the fluid responsiveness increase in stroke volume through echocardiography by $\geq 15 \%$ of basal cardiac output was considered responding - into 21 fluid responsive "R" (70\%) and 9 (30\%) non-responsive "NR" [24]. The overall mortality rate was $80 \%$ "24 patients" with no difference between responders and non-responders patients responsive
"R" (70\%) and 9 (30\%) non-responsive "NR." The overall mortality rate was $80 \%$ "24 patients" with no difference between responders and non-responders patients.

Monitoring hemodynamic parameters such as CVP did not have a significant change before and after fluid boluses. The two significant points about CVP were the higher values in NR and the narrow range in non-responders which reveal the nature of rigid venous reservoir in those patients (Table 2). Echocardiography was used to assess fluid assessment precisely by measuring aortic peak velocity + VTI variation and considered as the gold standard way to assess fluid status with sensitivity $76.2 \%$, specificity $88.9 \%$, and $p=0.013$. IVC parameters change during inspiration and expiration were unpredictive of volume responsiveness as they had insignificant change with the fluid bolus in responsive patients ( $p: 0.87)$. CDPV was significantly increased in response to increased intravascular volume in responsive group especially in comparison with IVC parameters with sensitivity $81 \%$, specificity $66.7 \%$, and $p=0.046$. There were no correlation between IVC parameters and carotid artery parameters. ROC curve was calculated for the use of $\triangle \mathrm{CDPV}$ as a diagnostic tool of fluid responsiveness in septic shock. The optimal cutoff point was $\geq 26 \%$ with a good sensitivity (Table 3 ).

Table 2: Responders versus non-responders main parameters before and after fluid boluses

\begin{tabular}{|c|c|c|c|}
\hline Variable & Responsive (n: 21) & Non-responsive (n: 9) & $\mathrm{p}$-value \\
\hline$\Delta \mathrm{CVP}$ & $5.86 \pm 5.22$ & $7.22 \pm 4.82$ & 0.689 \\
\hline \multicolumn{4}{|l|}{$\mathrm{CO}$} \\
\hline Before IV fluids & $5.26 \pm 4.42$ & $6.95 \pm 6.55$ & 0.722 \\
\hline After IV fluids & $10.62 \pm 5.73$ & $5.82 \pm 5.26$ & $0.011^{*}$ \\
\hline \multicolumn{4}{|l|}{ SV } \\
\hline Before IV fluids & $104.81 \pm 50.89$ & $115.56 \pm 82.56$ & 0.929 \\
\hline After IV fluids & $141.33 \pm 84.39$ & $95.22 \pm 61.67$ & $0.022^{*}$ \\
\hline \multicolumn{4}{|l|}{$\triangle \mathrm{D}-\mathrm{IVC}$} \\
\hline Before IV fluids & $11.91 \pm 9.41$ & $12.18 \pm 5.83$ & 0.449 \\
\hline After IV fluids & $13.51 \pm 9.56$ & $9.28 \pm 7.22$ & 0.104 \\
\hline \multicolumn{4}{|l|}{$\triangle \mathrm{CDPV}$} \\
\hline Before IV fluids & $24.43 \pm 11.87$ & $24.78 \pm 10.49$ & 1 \\
\hline After IV fluids & $33.22 \pm 11.00$ & $23.67 \pm 10.27$ & $0.045^{*}$ \\
\hline
\end{tabular}
Data were written as mean (standard deviation), $\triangle \mathrm{CDPV}$ : Respiratory variation in carotid Doppler peak
velocity, SV: Stroke volume, $\triangle \mathrm{D}$-IVC: Respiratory variation in inferior vena cavadiameter, CO: Cardiac output, CVP: Central venous pressure.

\section{Discussion}

Our study showed that $\triangle \mathrm{CDPV}$ was more precise and easier in interpretation than other older methods (CVP and respiratory variation in IVC-d) for evaluating fluid responsiveness in septic shock and mechanically ventilated patients. Furthermore, the $\triangle \mathrm{CDPV}$ has a high correlation with stroke volume index (SVI) increase after fluid boluses. Cardiac output and stroke volume measured by echocardiography had the highest significant values among the whole parameters that were measured either static or dynamic $(p=0.007$ and 0.01$)$, respectively, with sensitivity and 
Table 3: Cutoffs and diagnostic performances of significant predictors

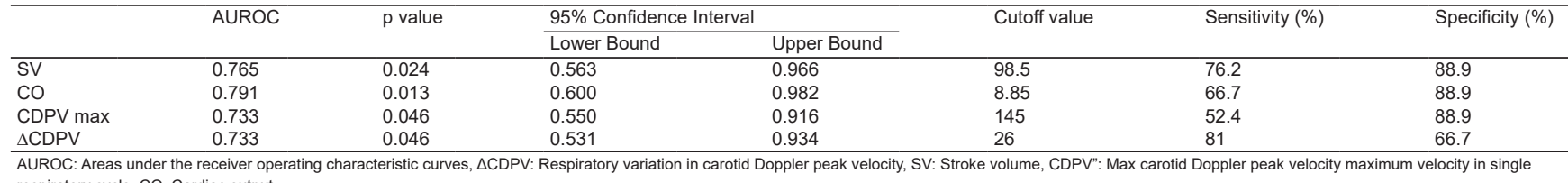

AUROC: Areas under the receiver operatich

specificity ( $86 \%$ and $89 \%$ ), respectively, and this proves that it should be the reference tool for any new tests evaluating fluid responsiveness. Similarly, Philippe Vignon et al. found that an increase of aortic blood flow of $10 \%$ or more during passive leg rising has a good sensitivity and specificity ( $97 \%$ and $94 \%$, respectively) in identifying fluid responders [24]. Moreover, another study concluded that respiratory variations in VTI can predict fluid responsiveness in ventilated patients, at a threshold of $20 \%$. Even though they proved that the respiratory variations in peak aortic flow predict fluid responsiveness in patients with septic shock under mechanical ventilation have a high sensitivity with a calculated threshold of $12 \%$ [25]. Furthermore, Feissel et al. reported high accuracy, sensitivity, and specificity ( $100 \%$ and $89 \%$, respectively) of respiratory variation in aortic blood velocity (cutoff value $>12 \%$ ) for prediction of fluid responsiveness in mechanically ventilated septic shock patients [26]. In the same time, CDPV shows the second higher specificity for fluid responsiveness after cardiac output measured by echocardiography. ( $p=0.012$, AUROC of $0.73,95 \%$ Cl: $0.531-0.934$ with sensitivity and specificity of 0.81 and 0.66 ) according to the statistical calculations: (Figure 2).

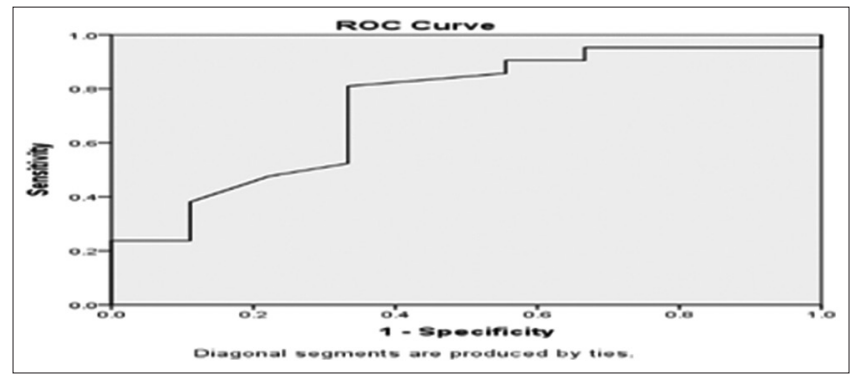

Figure 2: ROC curve for $\triangle C D P V$

Our results were nearly similar as Song et al. who conducted an analytical study on 40 patients postoperative elective coronary artery bypass surgery and divided patients as responders if SVI increased $\geq 15 \%$ after volume administration by IV bolus $6 \mathrm{ml} / \mathrm{kg}$. The CDPV was calculated as the difference between the highest and lowest values of peak velocity over a single respiratory cycle as our study and shows that the AUC of CDPV was 0.85 ( $p<0.001,95 \% \mathrm{Cl}: 0.72-0.97)$ with sensitivity and specificity of 0.83 and 0.82 ) [27]. It has a higher sensitivity and specificity compared to our study as the population of the study was more homogeneous than our patients (Post-CABG vs. Septic shock). On the same stream, Miguel et al. concluded that the $\triangle \mathrm{CDPV}$ had an AUROC of $0.88(95 \% \mathrm{Cl} 0.77-0.95)$ and has a superior predicting power for fluid responsiveness compared to stroke volume variation [14]. Besides the previous studies, an observational study was done on 49 patients of which 27 patients were classified as responders for the fluid challenge (responder group) and 22 as non-responders. There were no statistically significant differences in demographic and clinical variables while $\triangle \mathrm{CDPV}$ was found to be the best predictor of fluid responsiveness value for fluid responders (in comparison with stroke volume variation, ultrasound assessments of respiratory variations in IVC-d [ $\Delta \mathrm{IVC}]$, and brachial artery peak velocity). It was associated with $78 \%$ sensitivity and $90 \%$ specificity and AUC of 0.910 [28].

On the other hand, respiratory variation of IVC-d showed no significant change before and after fluid challenge $(11.91 \pm 9.41 \%$ vs. $13.51 \pm 9.56 \%$, respectively, with $p=0.87$ ). Our results were similar to the study done by Peter Bentzeret who carried out a large meta-analysis ( $n=173$ patients) which showed that $95 \% \mathrm{Cl}$ for likelihood ratios-the probability of the test to be positive in patients with the disease to probability to be positive in patients without disease - are wide values - the percentage of variation across studies - are high which indicate a high degree of heterogeneity [29]. Furthermore, Muller et al. found that in 40 spontaneously breathing shocked patients, the respiratory variations of IVC performed are not better than static indices of preload, such as measuring the pulmonary artery occlusion pressure. In this trial, respiratory variability in IVC-d $(>40 \%)$ was mostly fluid responsive, but lower values were not. Therefore, it does not have a significant threshold value [30]. However, on contrary to those studies, some studies such as Barbier et al. who studied the validity of respiratory variations in IVC to predict fluid responsiveness in mechanically ventilated patients and found that these measurements were initially validated in patients on mechanical ventilation, with 12 and $18 \%$ cutoff values separating fluid nonresponders from responders [31]. This discrepancy can be explained as IVC-d can be affected by multiple factors, for example, operators variance, the IVC can moving in and out of the plane of US beam with respiration, mimicking a false changes in measures. Moreover, work of breathing with any spontaneous ventilation has a significant impact on IVC size over the respiratory cycle [32]. 


\section{Conclusions}

Our study showed that $\triangle \mathrm{CDPV}$ was a more precise and even easier assessment tool with better sensitivity and specificity for evaluation of fluid responsiveness than the IVC-d in patients with septic shock on mechanical ventilation. Furthermore, $\triangle \mathrm{CDPV}$ has a high correlation with SVI increasing parameters assessed by echocardiography after fluid boluses. On the other hand and in comparison, CVP showed low accuracy in predicting fluid responsiveness. Echocardiography was still our gold standard method for fluid assessment as it showed very high specificity and sensitivity for fluid response.

\section{Limitations}

Other than the need for a well-trained operator for assessment of the IVC, carotid Doppler, and echography within a short time after admission of included patients for proper assessment of fluid response; there were no other limitations.

\section{Further studies}

We need further studies and meta-analysis to focus on carotid Doppler measurement against IVC-d or against echocardiography assessment to clarify the best method for evaluation of fluid responsiveness.

\section{References}

1. Levy MM, Evans LE, Rhodes A. The surviving sepsis campaign bundle: 2018 update. Intens Care Med. 2018;44(6):925-8. https://doi.org/10.1007/s00134-018-5085-0

PMid:29675566

2. Leisman DE, Doerfler ME, Ward MF, Masick KD, Wie BJ, Gribben JL. Survival benefit and cost savings from compliance with a simplified 3-hour sepsis bundle in a series of prospective, multisite, observational cohorts. Crit Care Med. 2017;45(3):395-406. https://doi.org/10.1097/ CCM.0000000000002184

PMid:27941371

3. Wiesenack C, Fiegl C, Keyser A, Prasser C, Keyl C. Assessment of fluid responsiveness in mechanically ventilated cardiac surgical patients. Eur J Anaesthesiol. 2005;22(9):658-65. https://doi.org/10.1017/s0265021505001092 PMid:16163911

4. Slama M, Masson H, Teboul JL, Arnould ML, Nait-Kaoudjt R, Colas $\mathrm{B}$, et al. Monitoring of respiratory variations of aortic blood flow velocity using esophageal Doppler. Intens Care Med. 2004;30(6):1182-7. https://doi.org/10.1007/s00134-004-2190-z PMid: 15004667

5. Liu V, Morehouse JW, Soule J, Whippy A, Escobar GJ. Fluid volume, lactate values, and mortality in sepsis patients with intermediate lactate values. AnnAm Thorac Soc. 2013;10:466-73.
https://doi.org/10.1513/AnnalsATS.201304-0990C

\section{PMid:24004068}

6. Vandervelden S, Malbrain ML. Initial resuscitation from severe sepsis: One size does not fit all. Anaesthesiol Intens Ther 2015;47:44-55. https://doi.org/10.5603/AIT.a2015.0075

PMid:26578400

7. Seymour CW, Gesten F, Prescott HC, Friedrich ME, Iwashyna TJ, Phillips GS, et al. Time to treatment and mortality during mandated emergency care for sepsis. N Eng J Med. 2017;376(23):2235-44. https://doi.org/10.1056/ NEJMoa1703058

8. Smith JS. Current recommendations for diagnosis and management of sepsis and septic shock. J Am Acad PAs. 2013;26(10):42-5. https://doi.org/10.1097/01. JAA.0000435007.55340.07

\section{PMid:24201922}

9. Mallat J, Meddour M, Durville E, Lemyze M, Pepy F, Temime J, et al. Decrease in pulse pressure and stroke volume variations after mini-fluid challenge accurately predicts fluid responsiveness. Br J Anaesth. 2015;115(3):449-56. https://doi. org/10.1093/bja/aev222

PMid:26152341

10. Lammi MR, Aiello B, Burg GT, Rehman T, Douglas IS, Wheeler AP, et al. Response to fluid boluses in the fluid and catheter treatment trial. Chest. 2015;148(4):919-26. https://doi. org/10.1378/chest.15-0445

PMid:26020673

11. Chen $\mathrm{C}$, Kollef MH. Conservative fluid therapy in septic shock: An example of targeted therapeutic minimization. Crit Care. 2014;18(4): 481. https://doi.org/10.1186/s13054-014-0481-5 PMid:25185073

12. Pinsky MR, Teboul JL. Assessment of indices of preload and volume responsiveness. Curr Opin Crit Care. 2005;11(3):235-9. https://doi.org/10.1097/01.ccx.0000158848.56107.b1 PMid:15928472

13. Michard F. Changes in arterial pressure during mechanical ventilation. Anesthesiology. 2005;103(2):419-28. https://doi. org/10.1097/00000542-200508000-00026 PMid: 16052125

14. Ibarra-Estrada MA, López-Pulgarín JA, Mijangos-Méndez JC Díaz-Gómez JL, Aguirre-Avalos G. Respiratory variation in carotid peak systolic velocity predicts volume responsiveness in mechanically ventilated patients with septic shock: A prospective cohort study. Crit Ultrasound J. 2015;7(1):12. https://doi. org/10.1186/s13089-015-0029-1

PMid:26123610

15. Dinh VA, Ko HS, Rao R, Bansal RC, Smith DD, Kim TE, et al Measuring cardiac index with a focused cardiac ultrasound examination in the ED. Am J Emerg Med. 2012;30(9):1845-51. https://doi.org/10.1016/j.ajem.2012.03.025 PMid:22795411

16. Zhu W, Wan L, Wan X, Wang G, Su M, Liao G, et al. Measurement of brachial artery velocity variation and inferior vena cava variability to estimate fluid responsiveness. Zhonghua Wei Zhong Bing Ji Jiu Yi Xue. 2016;28(8):713-7. https://doi. org/10.3760/cma.j.issn.2095-4352.2016.08.009 PMid:27434562

17. García MI, Cano AG, Monrové JC. Brachial artery peak velocity variation to predict fluid responsiveness in mechanically ventilated patients. Crit Care. 2009;13(5):R142. https://doi. org/10.1186/cc8027

PMid:19728876

18. Caillard A, Gayat E, Tantot A, Dubreuil G, M'Bakulu E, Madadaki C. Comparison of cardiac output measured by 
oesophageal Doppler ultrasonography or pulse pressure contour wave analysis. $\mathrm{Br} \mathrm{J}$ Anaesth. 2015;114(6):893-900. https://doi.org/10.1093/bja/aev001

PMid:25735709

19. Varas JL, Díaz CM, Blancas R, Gonzalez OM, Ruiz BL, Montero RM, et al. Inferior vena cava distensibility index predicting fluid responsiveness in ventilated patients. Intens Care Med Exp. 2015;3(Suppl 1):A600. https://doi. org/10.1186/2197-425X-3-S1-A600

20. Otto CM, Pearlman AS, Gardner CL, Enomoto DM, Togo $\mathrm{T}$, Tsuboi $\mathrm{H}$, et al. Experimental validation of Doppler echocardiographic measurement of volume flow through the stenotic aortic valve. Circulation. 1988;78:435-41. https://doi. org/10.1161/01.cir.78.2.435

21. Chan Y. Biostatistics 102: Quantitative data-parametric and non-parametric tests. Blood Pressure. 2003;140:79.

PMid: 14700417

22. Chan Y. Biostatistics 103: Qualitative data-tests of independence. Singapore Med J. 2003;44(10):498-503.

PMid:15024452

23. Chan Y. Biostatistics 104: Correlational analysis. Singapore Med J. 2003;44(12):614-9.

PMid:14770254

24. Vignon P, Repessé X, Bégot E, Léger J, Jacob C, Bouferrache K, et al. Comparison of echocardiographic indices used to predict fluid responsiveness in ventilated patients. Am J Respir Crit Care Med. 2017;195(8):1022-32. https://doi.org/10.1164/ rccm.201604-0844OC

25. De Backer D, Fagnoul D. Intensive care ultrasound: VI. Fluid responsiveness and shock assessment. Ann Am Thorac Soc. 2014;11(1):129-36. https://doi.org/10.1513/ AnnalsATS.201309-3200T PMid:24460447

26. Feissel M, Michard F, Mangin I, Ruyer O, Faller J, Teboul J. Respiratory changes in aortic blood velocity as an indicator of fluid responsiveness in ventilated patients with septic shock. Chest. 2001;119(3):867-73. https://doi.org/10.1378/ chest.119.3.867

PMid: 11243970

27. Song $Y$, Kwak $Y$, Song J, Kim Y, Shim J. Respirophasic carotid artery peak velocity variation as a predictor of fluid responsiveness in mechanically ventilated patients with coronary artery disease. Br J Anaesth. 2014;113(1):61-6. https:// doi.org/10.1093/bja/aeu057

PMid:24722322

28. Lu N, Xi X, Jiang L, Yang D, Yin K. Exploring the best predictors of fluid responsiveness in patients with septic shock. Am J Emerg Med. 2017;35(9):1258-61. https://doi.org/10.1016/j. ajem.2017.03.052

PMid:28363617

29. Bentzer P, Griesdale DE, Boyd J, MacLean K, Sirounis D, Ayas NT. Will this hemodynamically unstable patient respond to a bolus of intravenous fluids? JAMA. 2016;316(12):1298-309. https://doi.org/10.1001/jama.2016.12310 PMid:27673307

30. Muller L, Bobbia X, Toumi M, Louart G, Molinari N, Ragonnet B, et al. Respiratory variations of inferior vena cava diameter to predict fluid responsiveness in spontaneously breathing patients with acute circulatory failure: Need for a cautious use. Crit Care. 2012;16(5):R188. https://doi.org/10.1186/cc11672

31. Barbier $C$, Loubières $Y$, Schmit $C$, Hayon J, Ricôme JL, Jardin $F$, et al. Respiratory changes in inferior vena cava diameter are helpful in predicting fluid responsiveness in ventilated septic patients. Intens Care Med. 2004;30(9):1740-6. https://doi. org/10.1007/s00134-004-2259-8

PMid: 15034650

32. Charbonneau H, Riu B, Faron M, Mari A, Kurrek MM, Ruiz J, et al. Predicting preload responsiveness using simultaneous recordings of inferior and superior vena cavae diameters. Crit Care. 2014;18(5):473. https://doi.org/10.1186/ s13054-014-0473-5

PMid:25189403 